Document downloaded from:

http://hdl.handle.net/10251/164822

This paper must be cited as:

Amsler, J.; Sarma, BB.; Agostini, G.; Prieto González, G.; Plessow, P.; Studt, F. (2020). Prospects of Heterogeneous Hydroformylation with Supported Single Atom Catalysts. Journal of the American Chemical Society. 142(11):5087-5096. https://doi.org/10.1021/jacs.9b12171

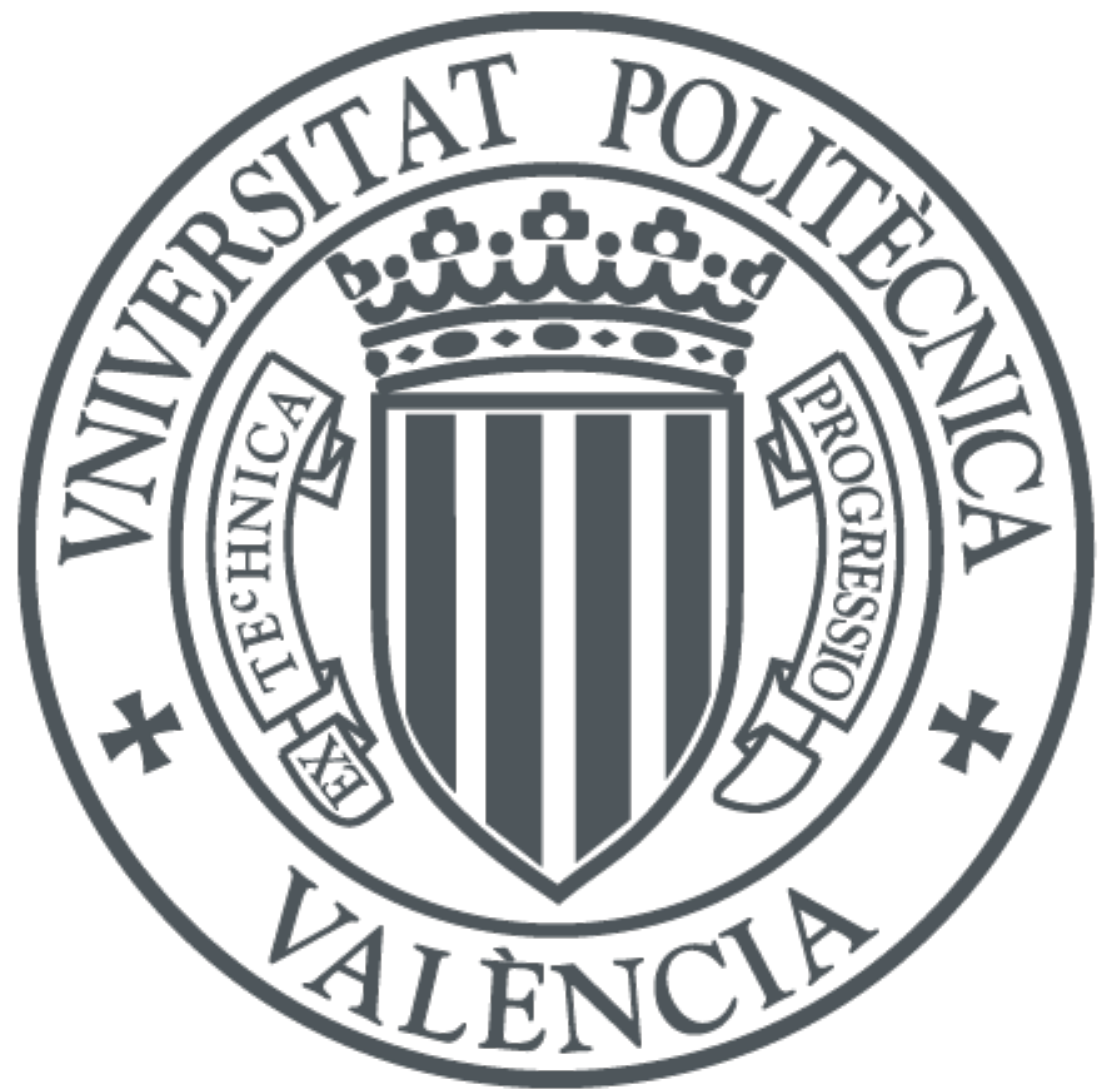

The final publication is available at

https://doi.org/10.1021/jacs.9b12171

Copyright American Chemical Society

Additional Information 


\title{
On the prospects of heterogeneous hydroformylation with supported single atom catalysts
}

\author{
Jonas Amsler ${ }^{\S}$, Bidyut B. Sarma ${ }^{\$}$, Giovanni Agostini ${ }^{\ddagger}$, Gonzalo Prieto ${ }^{\$ \dagger}$, Philipp N. Plessow ${ }^{\S *}$, Felix \\ Studt ${ }^{\S \#}$ \\ $\S$ Institute of Catalysis Research and Technology, Karlsruhe Institute of Technology, Hermann-von-Helmholtz Platz 1, 76344 \\ Eggenstein-Leopoldshafen, Germany. \\ \# Institute for Chemical Technology and Polymer Chemistry, Karlsruhe Institute of Technology, Kaiserstr. 12, 76131 \\ Karlsruhe, Germany. \\ \$ Max-Planck-Institut für Kohlenforschung, Kaiser-Wilhelm-Platz 1, 45470 Mülheim an der Ruhr, Germany. \\ ${ }^{\dagger}$ ITQ Instituto de Tecnología Química, Universitat Politécnica de València-Consejo Superior de Investigaciones Científicas \\ (UPV-CSIC), Av. Los Naranjos s/n, 46022 Valencia, Spain.
}

${ }^{\ddagger}$ ALBA Synchrotron Light Source, Carrer de la Llum 2-26, 08290, Cerdanyola del Vallès, Barcelona, Spain.

hydroformylation $\bullet$ single atom catalysis $\bullet$ heterogeneous catalysis $\bullet$ DFT $\bullet$ DLPNO-CCSD(T) $\bullet$ catalysis

\begin{abstract}
The potential of oxide-supported rhodium single atom catalysts (SACs) for heterogeneous hydroformylation was investigated both theoretically and experimentally. Using high-level DLPNO-CCSD(T) calculations, both stability and catalytic activity were investigated for Rh single atoms on different oxide surfaces. Atomically dispersed, supported Rh-catalysts were synthesized on $\mathrm{MgO}$ and $\mathrm{CeO}_{2}$. While the $\mathrm{CeO}_{2}$-supported rhodium catalyst is found to be highly active, this is not the case for $\mathrm{MgO}$, most likely due to increased confinement, as determined by EXAFS, that diminishes the reactivity of Rh complexes on MgO. This agrees well with our computational investigation, where we find that rhodium carbonyl hydride complexes on flat oxide surfaces such as $\mathrm{CeO}_{2}(111)$ have catalytic activities comparable to those of molecular complexes. For a step edge on a $\mathrm{MgO}(301)$ surface, however, calculations show a significantly reduced catalytic activity. At the same time, calculations predict that stronger adsorption at the higher coordinated adsorption site leads to a more stable catalyst. Keeping the balance between stability and activity appears to be the main challenge for oxide supported Rh hydroformylation catalysts. In addition to the chemical bonding between rhodium complex and support, the confinement experienced by the active site plays an important role for the catalytic activity.
\end{abstract}

\section{INTRODUCTION}

Hydroformylation is one of the most relevant industrial processes for the production of aldehydes from olefins and synthesis gas $\left(\mathrm{H}_{2}, \mathrm{CO}\right) .{ }^{1}$ Aldehydes are an important feedstock for alcohols, amines and carboxylic acids, in particular dialkyl phthalates as plasticisers. ${ }^{1}$ Rh-complexes employing phosphine and phosphite ligands are commonly used as homogeneous catalysts, both in academic and industrial applications. Costintensive recycling and losses due to leaching ${ }^{2}$ of rhodium are the main drawback of this approach.

There have been several approaches to anchor rhodium clusters, $^{3}$ dimers $^{4}$ or well-defined monoatomic rhodium complexes on the surface of oxides ${ }^{5}, 6$ or phosphinefunctionalized polymers., 8 Among these concepts, the synthesis of atomically dispersed, oxide-supported single atom catalysts (SACs) is also very promising. ${ }^{9}$ Ideally consisting of dispersed single metal atoms on a solid support, these materials feature isolated active sites and utilize the precious metal efficiently. They thus combine the advantages of homogeneous and heterogeneous catalysis, through well-defined reaction centers and efficient separation of the catalyst from the reaction medium. ${ }^{10}$ Within heterogeneous catalysis, this concept is best comparable to isolated active single sites in zeolite materials such as $\mathrm{Cu}-\mathrm{SSZ}-13{ }^{11,12}$ While literature provides hints that SACs are promising for hydroformylation, ${ }^{9,} 13$ their general potential has not been investigated in depth.

The mechanism of the homogeneously catalyzed hydroformylation proposed by Heck and Breslow is widely accepted. ${ }^{14,15}$ An adaptation for SACs with carbonyl ligands only is presented in Scheme 1. The actual number of carbonyl ligands is expected to depend on the support. The elementary steps comprise activation of the catalyst by dissociation of one ligand (1->2), olefin coordination (2->3), olefin insertion (3(TS1)->4), CO coordination (4->5), CO insertion (5-(TS2)->6), oxidative addition of $\mathrm{H}_{2}(\mathbf{6}-(\mathbf{T S 3})->8)$ and reductive elimination of the resulting aldehyde (8-(TS4)->2) with four transition states (TS). Experimental and theoretical studies find the rate determining step of the homogeneous reaction to strongly depend on the reaction conditions, the olefin, the catalyst and potentially mass transfer limitations. ${ }^{16-18}$ According to Sparta et al. electron-withdrawing ligands lead to rate-determining hydrogenolysis whereas more electron-donating ligands shift the barriers towards rate-determining coordination-insertion of the olefin. ${ }^{18}$ Ligand effects are substantial and have been investigated experimentally and computationally ${ }^{19,20}$ for mono- 


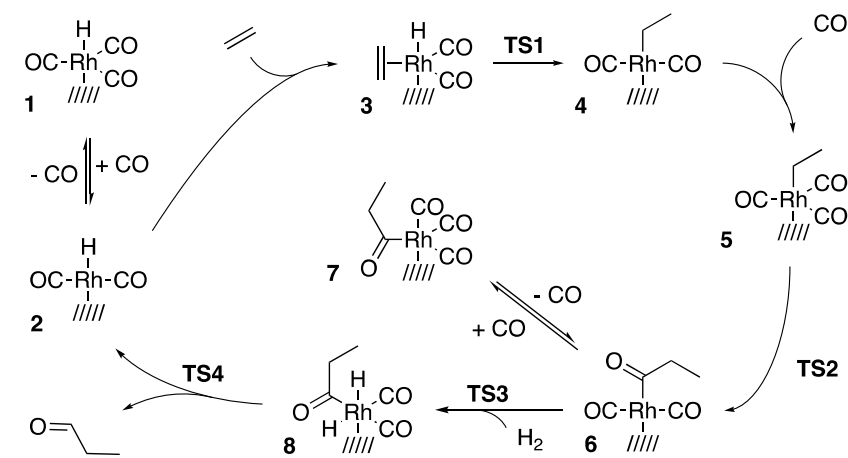

Scheme 1. Heck and Breslow mechanism adapted for heterogeneous hydroformylation on supported SAC.

${ }^{17}$ and bidentate ${ }^{21,22}$ ligands. ${ }^{23}$ On the theoretical side, many facets of the homogeneous hydroformylation have been investigated. ${ }^{24}$ Gellrich et al. described the effect of assembled bidentate ligands. ${ }^{19}$ Scaling relations have been derived for the metals in groups 8, 9 and $10 .^{25}$ Jacobs et al. investigated industrially relevant triphenylphosphine rhodium complexes using density functional theory (DFT). ${ }^{23}$

SACs have been used successfully ${ }^{26}$ for e.g. the selective activation of methane for direct conversion to methanol ${ }^{27}$ or $\mathrm{CO}$ oxidation. $^{28}$ These catalysts have become accessible by preparation procedures ranging from atomic layer deposition (ALD), ${ }^{29}$ mass-selected soft-landing, ${ }^{30}$ and a variety of wet chemistry anchoring methods ${ }^{31,32}$ to metal re-dispersion ${ }^{33}$ and pyrolysis synthesis. ${ }^{34}$ Characterization techniques range from microscopy (HAADF-STEM, AFM) ${ }^{9}$ to spectroscopy

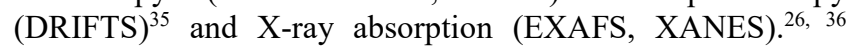
Density functional theory (DFT) has also been used to gain a fundamental understanding of the properties of SACs. For instance, ceria oxide supports appear to inhibit sintering and Neitzel et al. found that $\mathrm{M}^{2+}$ species $(\mathrm{M}=\mathrm{Pt}, \mathrm{Pd}, \mathrm{Ni})$ possess higher adsorption energies on a $\left[\mathrm{CeO}_{2}\right]_{40}$ cluster than their corresponding cohesive energies in the bulk metals. ${ }^{37,} 38$ Meanwhile, it has been shown that $\mathrm{Rh}^{39}$ and $\mathrm{Pt}^{40}$ single atoms on titanium oxide dynamically respond to reaction conditions. A computational framework involving DFT and kinetic Monte Carlo simulations to predict the stability of SACs against sintering was presented by $\mathrm{Su}$ et al. $^{41}$ Trends in stability of supported single atom catalysis were also investigated by O'Connor et al. ${ }^{42}$

In this work, we investigate the catalytic activity and stability of oxide-supported Rh SACs both computationally and experimentally. We will first study the stability of atomically dispersed $\mathrm{Rh}$ with respect to desorption on various surfaces using DFT and coupled cluster calculations. The catalytic activity is then investigated by computing reaction barriers for the mechanism shown in Scheme 1 for the most promising oxide supports. Last, various oxide-supported Rh-catalysts are prepared and characterized using XRD, HAADF-STEM and EXAFS. The activity of Rh deposited on various supports is tested in hydroformylation reactions and is then compared to results obtained from calculations.

\section{METHODS}

Density Functional Theory (DFT): All structures were optimized with the $\mathrm{PBE}^{43}$ density functional with the D3 dispersion correction (zero damping) developed by Grimme ${ }^{44}$ (PBE-D3) using VASP with the standard PAW and an energy cutoff of $400 \mathrm{eV}(800 \mathrm{eV}$ for optimization of lattice constants). ${ }^{45-47}$ Convergence criteria of $10^{-8} \mathrm{eV}$ and $0.01 \mathrm{eV} / \AA$ were applied to SCF-cycles and geometry optimization. For $\mathrm{CeO}_{2}$, the $\mathrm{DFT}+\mathrm{U}$ method using an $\mathrm{U}$ parameter of $5 \mathrm{eV}$ for cerium 4 f-electrons was employed. ${ }^{48-50}$ The Brillouin-zone was sampled using a $\Gamma$-centered k-point grid $^{51}(3,3,1)$ and Gaussian smearing with a width of $0.1 \mathrm{eV}$. The top two layers and the adsorbates were relaxed in the optimization, while the bottom layers were kept frozen at their bulk positions. Slabs were separated by $16 \AA$ of vacuum. Free energies corrections at $363 \mathrm{~K}$ and a reference pressure of 10 bar were obtained with the rigid-rotator harmonic-oscillator approximation. The partial hessian matrix was computed using a central finite differences scheme including only the adsorbates. Transition states were located using the ARPESS algorithm and verified to have only one imaginary harmonic frequency corresponding to the transition vector of the reaction connecting the correct minima. ${ }^{52}$ Additional DFT ${ }^{53,54}$ and ab initio calculations with Gaussian basis sets were carried out with Turbomole ${ }^{55-57}$ and ORCA $^{58-62}$. Our computational investigation focuses on gas phase reactions and we do therefore not incorporate solvent effects. We have studied the effect of solvation in toluene for the molecular catalysts $\mathrm{HRh}(\mathrm{CO})_{4}$ and $\mathrm{HRh}(\mathrm{CO})_{3} \mathrm{PMe}_{3}$ and have found that the solvation contribution to individual steps is typically below $10 \mathrm{~kJ} / \mathrm{mol}$ (see SI for details). Most importantly, solvent corrections are similar for the different catalysts, the comparison of trends obtained without solvation correction is thus a reasonable approximation.

DLPNO-CCSD(T): The experimental gas phase reaction enthalpy $\Delta_{r} H^{0}$ for the hydroformylation of ethene is not well reproduced by PBE-D3 (error of $49.4 \mathrm{~kJ} / \mathrm{mol}$, see Table S1). With an error of only $5 \mathrm{~kJ} / \mathrm{mol}$ for the same reaction, DLPNO$\operatorname{CCSD}(\mathrm{T})$ is an accurate and efficient approximation to canonical CCSD(T). Hence, we correct the DFT barriers of the molecular catalysts and a cluster model of $\mathrm{Rh}_{1} / \mathrm{MgO}(100)$ with single point energy calculations using DLPNO-CCSD $(\mathrm{T})^{63}$ and the def2-TZVPP basis $\operatorname{set}^{57}$ using the ORCA program. ${ }^{58,59}$

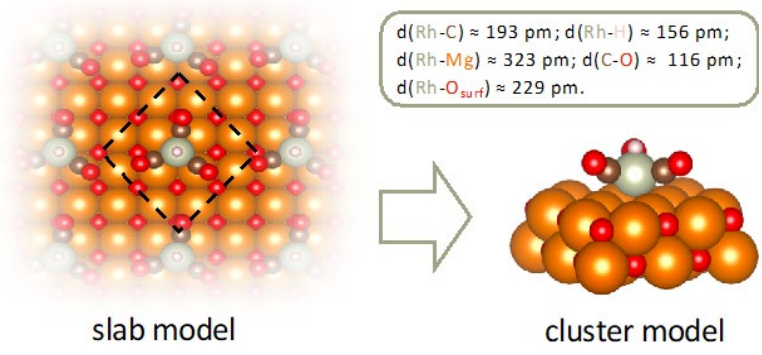

Figure 1. The periodic slab model with four metal oxide layers and the non-periodic cluster model with two layers. Bond distances between $\mathrm{Rh}$ and ligands are given in $\mathbf{p m}$.

The cluster model in Figure 1 with two oxide layers was obtained from the slab model with four layers. The reaction energy differences between the cluster and the slab model were used as a correction term in our hybrid high-level cluster:lowlevel periodic approach (DLPNO-CCSD(T):PBE-D3) according to eq. 1 (see Figure S1 for a detailed analysis).

$E_{\text {final }}^{\text {hyb. }}=E_{\mathrm{DLPNO}-\mathrm{CCSD}(\mathrm{T})}^{\text {cluster model }}+E_{\mathrm{PBE}-\mathrm{D} 3}^{\text {slab model }}-E_{\mathrm{PBE}-\mathrm{D} 3}^{\text {cluster model }}$ 
Similar procedures were employed by Ugliengo et al. ${ }^{64}$ and Sauer and coworkers. ${ }^{65}$

Trends with DFT and DLPNO-CCSD(T): Besides the absolute values of reaction energies and barriers that determine the activity and selectivity of a catalyst, we are also focusing on how changing the catalyst would affect certain reaction steps, for example by lowering a certain barrier. Trends among catalysts can be studied through the differences in reaction energy $(\Delta \Delta E)$ for each intermediate and transition state for a catalyst with respect to a reference catalyst. The procedure is shown in Figure 2, using $\mathrm{HRh}(\mathrm{CO})_{4}$ as a reference catalyst (Figure 2a shows how $\Delta \Delta E$ is derived). In Figure $2 \mathrm{~b}, \Delta \Delta E$ obtained for PBE-D3 is compared to differences calculated with the DLPNO-CCSD $(\mathrm{T})$ approach in a parity plot. As can be seen from Figure 2, there is generally a good correlation between $\Delta \Delta E$ for PBE-D3 and DLPNO-CCSD(T) with a mean absolute error (MAE) of only $5.4 \mathrm{~kJ} / \mathrm{mol}$. Calculations employing PBED3 are hence able to predict differences in reactivity between different catalysts. Importantly, the trends between different catalysts are thus well described by DFT while absolute values require higher level methods. The fact that differences in the energetics between different materials are predicted well by PBE-D3 can be exploited to obtain accurate absolute values for barriers and reaction energies. If the energies are available at the DLPNO-CCSD(T) level of theory for a given catalyst, predictions for other catalysts can be made based on the energy difference computed with PBE-D3. This approach was applied for $\mathrm{Rh}_{1} / \mathrm{MgO}(301)$ and $\mathrm{Rh}_{1} / \mathrm{CeO}_{2}(111)$ using $\mathrm{Rh}_{1} / \mathrm{MgO}(100)$ as a reference catalyst. In these cases, the energies were obtained as:

$E_{\mathrm{predicted}}^{\mathrm{SAC}}=E_{\mathrm{DLPNO}-\mathrm{CCSD}(\mathrm{T})}^{\text {ref. }}+E_{\mathrm{PBE}-\mathrm{D} 3}^{\mathrm{SAC}}-E_{\mathrm{PBE}-\mathrm{D} 3}^{\mathrm{ref}}$

More technical details, energies and Cartesian coordinates are provided in the supporting information (SI).

Catalyst preparation: $\mathrm{CeO}_{2}$ was synthesized by calcination of $\mathrm{Ce}\left(\mathrm{NO}_{3}\right)_{3} \cdot 6 \mathrm{H}_{2} \mathrm{O}$ (Sigma-Aldrich, $99.99 \%$ ) in air at $623 \mathrm{~K}$ for $2 \mathrm{~h}$. $\mathrm{MgO}$ was synthesized via a xerogel route. ${ }^{66}$ In a typical synthesis, $100 \mathrm{~mL}$ of a $\mathrm{Mg}(\mathrm{II})$ methoxide solution $(7-8 \%$ in methanol, Sigma-Aldrich) were diluted in $1 \mathrm{~L}$ toluene (technical grade). Next, milli-Q water was added dropwise at RT and the suspension was stirred overnight to enable a complete hydrolysis of the alkoxide precursor. The resulting gel was collected by centrifugation, dried at $353 \mathrm{~K}$ and calcined under air flow in a fixed-bed reactor at $773 \mathrm{~K}$ for $5 \mathrm{~h}$ (heating rate: $2 \mathrm{~K} / \mathrm{min}$ ). For the synthesis of oxide-supported $\mathrm{Rh}$ catalysts, $\mathrm{Rh}$ (III)-acetylacetonate (Sigma-Aldrich, 97\%) was dissolved in acetone and impregnated on the oxide support in a rotary evaporator $(430 \mathrm{mbar}, 313 \mathrm{~K})$. The solid was further dried at $353 \mathrm{~K}$ in an oven overnight and ground into a powder. The resulting powder was calcined in an uncapped porcelain dish (50 mm diameter) at $1073 \mathrm{~K}$ under a stagnant air atmosphere for $10 \mathrm{~h}$ using a temperature ramp from RT of $2 \mathrm{~K} / \mathrm{min}$. Finally, the catalyst was ground and sieved to retain particles in the 100-200 $\mu \mathrm{m}$ size range. The metal content was adjusted to achieve a pre-set surface-specific $\mathrm{Rh}$ content (after the high-temperature annealing treatment) of $1.0 \pm 0.2 \mathrm{M}_{\mathrm{at}} / \mathrm{nm}^{2}$.

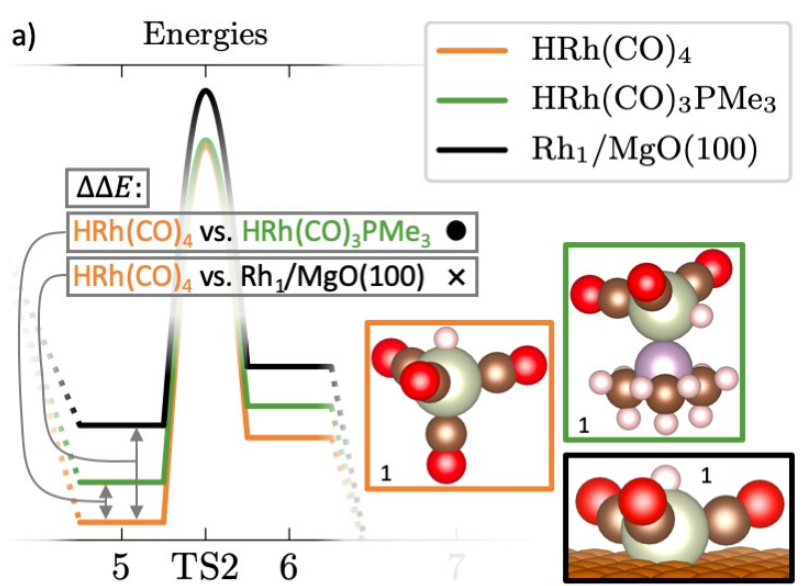

Reaction coordinate

b)

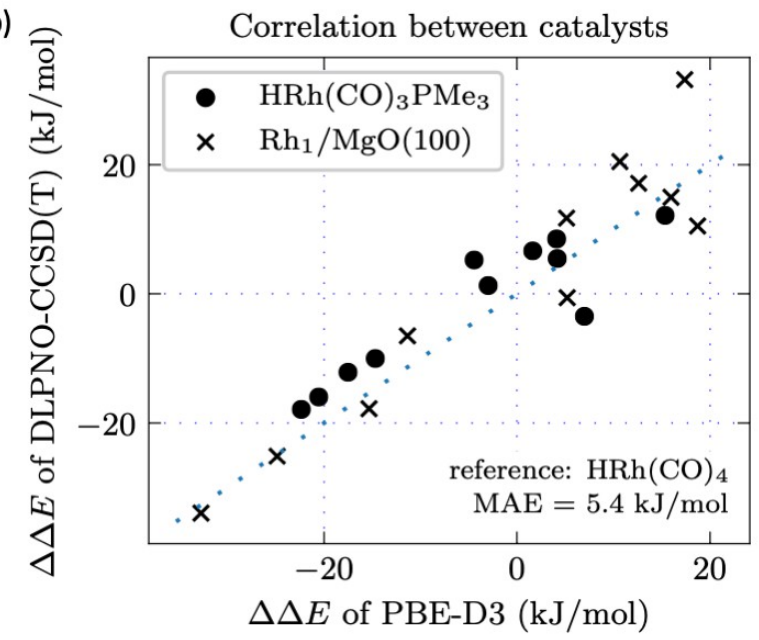

Figure 2. Correlation of the PBE-D3 and the DLPNOCCSD(T) approach. - a) Definition of $\Delta \Delta E$ as differences in reaction energy between different catalysts from intermediate 2 to all other intermediates. The reaction to itself is not included. - b) Parity plot showing the correlation of $\Delta \Delta E$ for the two methods employed.

Catalyst characterization: Nitrogen physisorption isotherms were recorded at $77 \mathrm{~K}$ using a Micromeritics 3Flex V4.04 instrument. Prior to the measurement, samples were dried at $423 \mathrm{~K}$ under vacuum for $5 \mathrm{~h}$. Specific surface areas were derived using the BET method in the relative pressure $\left(\mathrm{P} / \mathrm{P}_{0}\right)$ regime of $0.05-0.30$. Powder $\mathrm{X}$-ray diffraction patterns were collected on a Stoe STADI $P$ transmission diffractometer equipped with a primary $\mathrm{Ge}(111)$ monochromator (MoK $\alpha 1)$ and a position-sensitive detector. Samples were filled into glass capillaries $(\varnothing=0.5 \mathrm{~mm})$. Data were collected in the $2 \theta$ range between $5^{\circ}$ and $50^{\circ}$ with a step width of $0.015^{\circ}$ and a measuring time per step of $20 \mathrm{~s}$. For each sample, 8 scans were collected and summed up. High-angle annular dark-field (HAADF) micrographs were acquired using a Hitachi HD-2700 dedicated Scanning Transmission Electron Microscope (STEM) with spherical aberration correction, equipped with a cold fieldemission gun and two EDAX Octane T Ultra W EDX detectors and operated at $200 \mathrm{kV}$. Powder samples were dry-cast on $\mathrm{Cu}$ grids coated with a lacey carbon film prior to observation. XRay absorption spectra were recorded at the RhK edge $(23.220 \mathrm{keV})$, at the CLÆSS beamline station (BL22) of the ALBA synchrotron light source, Barcelona (Spain). The beam 
was monochromatized using a (311) double crystal monochromator and harmonic rejection was performed using Pt-coated silicon mirrors. Samples were mounted in a multipurpose gas-solid cell equipped with Kapton windows and measurements were performed at room temperature in a fluorescence mode using a fluorescence solid-state Silicon Drift detector. Reference metal oxide materials were ground and diluted in powder boron nitride and shaped into pellets $(\varnothing=31 \mathrm{~mm})$ with optimized thickness and measured in transmission mode employing ion chambers filled with appropriate gases in order to adsorb $15 \%$ and $80 \%$ in the $\mathrm{I}_{0}$ and $\mathrm{I}_{1}$, respectively. At least 3 scans were acquired to ensure spectral reproducibility and good signal-to-noise ratio. The same cell was applied to study the $\mathrm{Rh}_{1} / \mathrm{CeO}_{2}$ catalyst during and after exposure to a syngas reaction atmosphere. The catalyst sample was exposed to a continuous syngas $\left(\mathrm{H}_{2} / \mathrm{CO}=1\right)$ flow of $50 \mathrm{~mL} / \mathrm{min}$ at atmospheric pressure and the temperature was increased from RT to $373 \mathrm{~K}$. XANES spectra were recorded in a temperature-resolved manner, in fluorescence mode, through the entire temperature range, while the EXAFS spectra were recorded, at room temperature, both prior and after the treatment to study changes in the coordination environment of the $\mathrm{Rh}$ sites. Data reduction and extraction of the $\chi(\mathrm{k})$ function has been performed using Athena code. EXAFS data analysis has been performed using Artemis (Demeter software package). ${ }^{67}$

Catalyst testing: Catalytic tests were performed in a stainless steel autoclave reactor hosting a $20 \mathrm{~mL}$ PTFE liner. The powder solid catalyst $(0.002 \mathrm{mmol}$, $\mathrm{Rh}$ basis $), 5 \mathrm{~mL}$ of solvent, typically 1-octane ( $>99 \%$, Sigma-Aldrich), and $1 \mathrm{mmol}$ of olefin substrate were added to the reactor. For experiments requiring time-resolved sampling from the reactor, the initial olefin concentration and solvent volume were increased to $5 \mathrm{mmol}$ and $15 \mathrm{~mL}$, respectively, maintaining an olefin:Rh molar ratio of 500:1. Next, a synthetic syngas mixture $\left(\mathrm{CO}: \mathrm{H}_{2}=1: 1\right)$ was fed up to a total pressure of 10 bar at room temperature. The reactor was mounted on an aluminum heating block coupled to a stirring plate, the temperature ramped up to the reaction temperature $(2 \mathrm{~K} / \mathrm{min})$ and the reaction performed under vigorous magnetic stirring. After preset reaction times, the liquid reaction medium was sampled through a capillary equipped with a porous frit $(2 \mu \mathrm{m}$ opening size $)$. Reaction products were identified by gas chromatography in an ISQ chromatograph coupled to a Quadrupole Mass Spectrometer and a Q-Exactive GC Orbi trap (Thermo Scientific). The progress of the reaction was monitored using gas chromatography (GC) in a Shimadzu QP2010 Plus gas chromatograph, equipped with a ZB-1HT Inferno column $(30 \mathrm{~m}, 0.25 \mathrm{~mm} \mathrm{ID,} \mathrm{df} 0.25 \mu \mathrm{m})$ and a Flame Ionization Detector (FID) using $\mathrm{N}_{2}$ as carrier gas and mesitylene as internal standard. Turnover frequency (TOF) values were determined from initial olefin hydroformylation rates (extrapolated to zero reaction time) and expressed on a total Rh atom basis. Hot filtration tests were performed in the same reactor, filtering the reaction liquor through a porous frit $(2 \mu \mathrm{m}$ opening size) under reaction conditions after a preset olefin conversion degree $(<50 \%)$ had been achieved. This procedure was repeated twice to ensure full exclusion of catalyst fines, additional olefin substrate was added to the filtrate and another reaction batch was carried out without further addition of catalyst.

\section{RESULTS AND DISCUSSION}

Theoretical investigation of catalyst stability: Desorption of the active rhodium complex into the gas phase or leaching into solution is expected to be the main pathway for deactivation of SACs. To assess the stability of a catalyst, we have therefore calculated the formation free energy of the supported rhodium catalyst with respect to the most stable gas phase complex, $\mathrm{HRh}(\mathrm{CO})_{4}$, see Figure 3.

a)

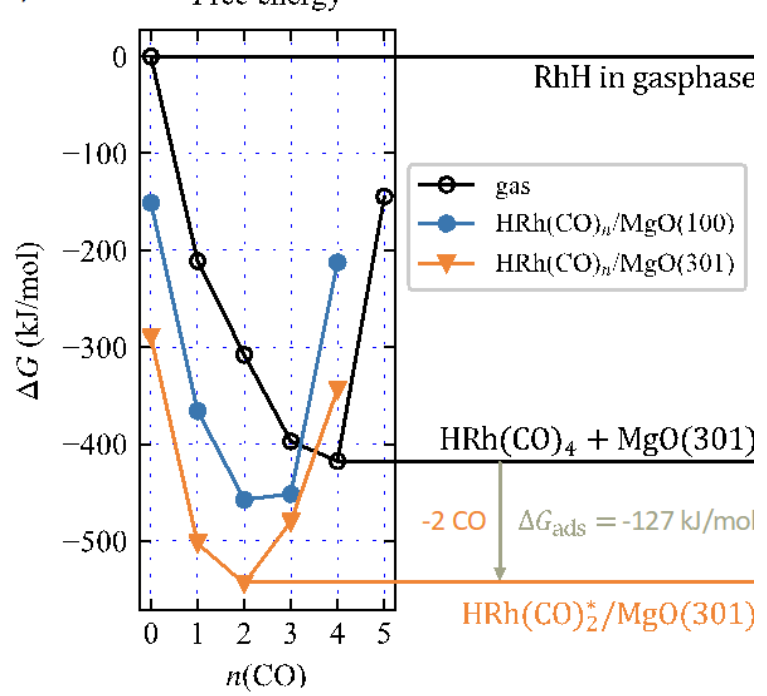

b)

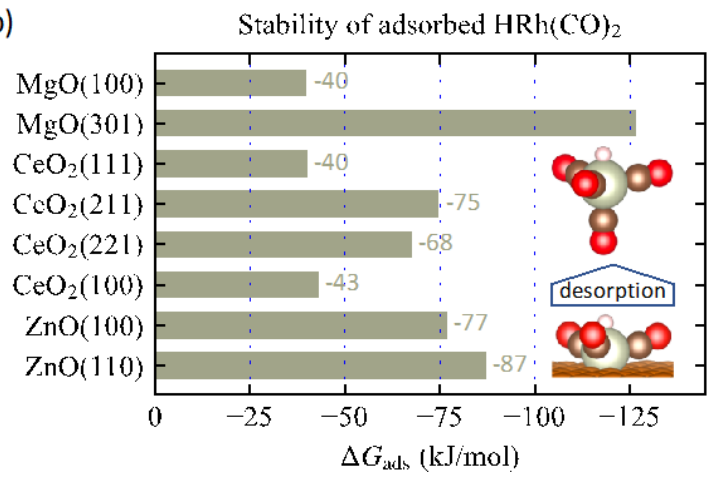

Figure 3. Procedure to obtain adsorption free energies at $363 \mathrm{~K}$ and $10 \mathrm{bar}$ - - a) Free energy as a function of the number of carbonyl ligands $n(\mathrm{CO})$. - b) Adsorption free energies for different SACs.

Importantly, we considered that the most stable complex on the supports always contains less carbonyl ligands, as illustrated in Figure 3a and shown in eq. 3.

$\Delta G_{\mathrm{ads}}=\min _{\mathrm{n}_{1}}\left(G_{\mathrm{HRh}(\mathrm{CO})_{n_{1}}}^{\mathrm{SAC}}\right)-\min _{\mathrm{n}_{2}}\left(G_{\mathrm{HRh}(\mathrm{CO})_{n_{2}}}^{\text {gas }}\right)$

All Rh-complexes were adsorbed on top of the surfaces or at edges, where $\mathrm{Rh}$ is typically coordinated to one or two oxygen atoms. Exchange of $\mathrm{Rh}$ into cation positions in the surface or subsurface was not studied. The most stable rhodium complex on the investigated supports, $\mathrm{HRh}(\mathrm{CO})_{2}$, contains two carbonyl ligands. Typically, complexes with three carbonyl ligands are almost equally stable on flat surfaces with low geometric confinement (i.e. a low coordination number of Rh-O), whereas more open surfaces that allow for polydentate binding significantly destabilize structures with more than two carbonyl ligands. This is the case for surfaces containing steps, such as 
$\mathrm{MgO}(301)$ and $\mathrm{CeO}_{2}(211)$ and $\mathrm{CeO}_{2}(221)$, while flat surfaces such as $\mathrm{MgO}(100)$ and $\mathrm{CeO}_{2}(111)$ facilitate the adsorption of a third carbonyl ligand. The different number of carbonyl ligands between the most stable complexes on different supports and in the gas phase leads to a strong dependence of the stability on temperature and CO-pressure (see the SI for a detailed analysis as a function of temperature, Figures S2 and S3). By far the highest adsorption free energy was found for the step of $\mathrm{MgO}(301)$ with over $-127 \mathrm{~kJ} / \mathrm{mol}$. This is more than three times the adsorption energy on flat $\mathrm{MgO}(100)$. $\mathrm{MgO}(301)$ is followed by the two $\mathrm{ZnO}$ surfaces with adsorption free energies of $87 \mathrm{~kJ} / \mathrm{mol}$ and $-77 \mathrm{~kJ} / \mathrm{mol}$. The comparatively high stability of rhodium SACs on $\mathrm{ZnO}$ is in line with experiments showing single atom $\mathrm{Rh}_{1} / \mathrm{ZnO}$-nanowires to be active and recyclable hydroformylation catalysts. ${ }^{9}$ According to the observed trends in Figure $3 \mathrm{~b}$, some flat $\mathrm{CeO}_{2}$ facets show low adsorption free energies, and Rh-complexes supported on those surfaces are therefore more likely to be deactivated through desorption, or are expected to adsorb at more stable corrugated sites.

Theoretical investigation of the catalytic activity: For simplicity, we will study ethene as the substrate. We have, however, confirmed that trends in the reactivity are essentially the same for ethene and styrene employing $\mathrm{HRh}(\mathrm{CO})_{4}$ and $\mathrm{HRh}(\mathrm{CO})_{3} \mathrm{PMe}_{3}$ (see the SI). The hydroformylation of ethene to propanal is exothermic and the experimental reaction enthalpy at $\mathrm{T}=298.15 \mathrm{~K}$ is well reproduced computationally (see method section and Table $\mathrm{S} 1$ ).

$\mathrm{C}_{2} \mathrm{H}_{4}+\mathrm{CO}+\mathrm{H}_{2} \rightarrow \mathrm{C}_{2} \mathrm{H}_{5} \mathrm{CHO} \quad \Delta_{r} H_{\exp }^{298.15 K}=-127.9 \mathrm{~kJ} / \mathrm{mol}^{68,69}$

We will study $\mathrm{MgO}(100), \mathrm{MgO}(301)$ and $\mathrm{CeO}_{2}(111)$ as oxide supports. Additionally, $\mathrm{HRh}(\mathrm{CO})_{4}$ and $\mathrm{HRh}(\mathrm{CO})_{3} \mathrm{PMe}_{3}$ were included in the investigation as a comparison with molecular complex catalysts. The resting states for the catalytic cycles were identified based on the stability study: One CO ligand was removed from the molecular rhodium carbonyl complex $\mathrm{HRh}(\mathrm{CO})_{4}$ when adsorbed on the flat surfaces $\mathrm{MgO}(100)$ and $\mathrm{CeO}_{2}$ (111) leading to the structures in Scheme 1. Two CO ligands were removed from the $\mathrm{HRh}(\mathrm{CO})_{4}$ when adsorbed at the step of $\mathrm{MgO}(301)$. The mechanism at the step of $\mathrm{MgO}(301)$ is equivalent to Scheme 1 but with one CO ligand less for every intermediate. The free energy profiles for the homogenous catalysts $\mathrm{HRh}(\mathrm{CO})_{4}$ and $\mathrm{HRh}(\mathrm{CO})_{3} \mathrm{PMe}_{3}$ compared to $\mathrm{Rh}_{1} / \mathrm{MgO}(100)$ calculated at the DLPNO-CCSD(T) level of theory are shown in Figure $4 \mathrm{a}$. Figure $4 \mathrm{~b}$ shows the reaction energy profile for $\mathrm{Rh}_{1} / \mathrm{MgO}(100)$

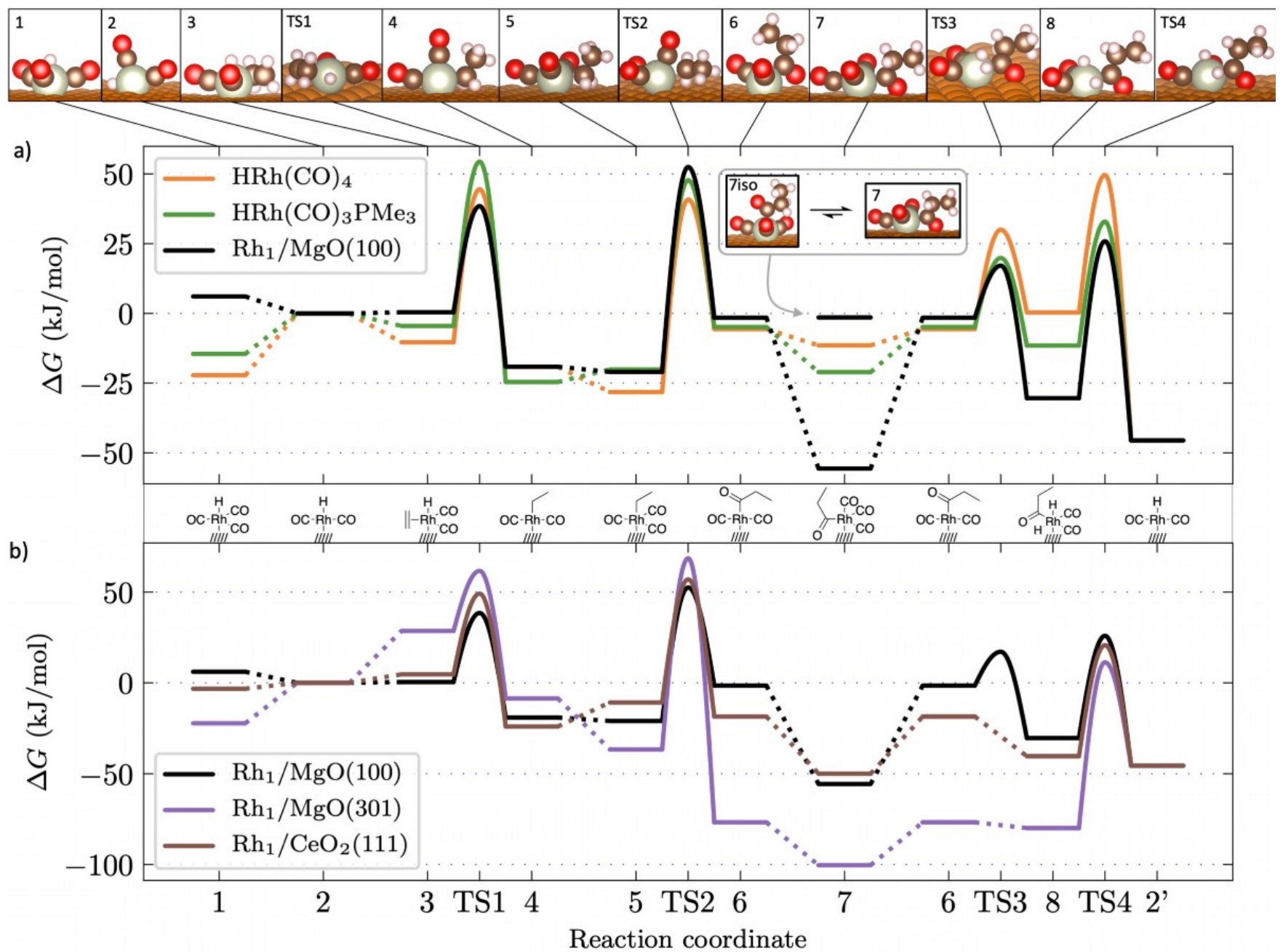

Figure 4. Activity of supported single atom catalysts (SACs) and molecular catalysts in hydroformylation in gas phase at $363 \mathrm{~K}$ and 10 bar (details in Figure S4). - a) Comparison of the supported SAC Rh $/$ MgO(100) to the two molecular catalysts $\mathrm{HRh}(\mathrm{CO})_{4}$ and $\mathrm{HRh}(\mathrm{CO})_{3} \mathrm{PMe}_{3}$. - b) Comparison of SACs supported on different metal oxides predicted using differences computed at the PBE-D3 level of theory. 
in comparison to that of $\mathrm{Rh}_{1} / \mathrm{MgO}(301)$ and $\mathrm{Rh}_{1} / \mathrm{CeO}_{2}(111)$ using differences between catalysts at the DFT level. A justification of this approach is presented in Figure $2 b$ of the method section. Comparing $\mathrm{Rh}_{1} / \mathrm{MgO}(100)$ to molecular catalysts shows that they have fairly similar reaction barriers with the main difference being the high stability of intermediate 7 and 8. This can be attributed to an attractive interaction between the carbonyl oxygen of the propionyl rest and the support. This interaction, however, was not observed for other intermediates on $\mathrm{Rh}_{1} / \mathrm{MgO}(100)$. An isomer 7iso with the surface in axial position is destabilized but energetically more similar to the molecular catalysts. Interaction of the surface with the carbonyl oxygen of the propionyl rest is also an explanation for the lower free energies of steps 6, 7, 8 and TS4 of the other SACs, particularly the highly confined $\mathrm{Rh}_{1} / \mathrm{MgO}(301)$. At $363 \mathrm{~K}$ and a reference pressure of $10 \mathrm{bar}$, the highest effective barriers for $\mathrm{HRh}(\mathrm{CO})_{4}$ and $\mathrm{Rh}_{1} / \mathrm{MgO}(100)$ were found for those involving TS4, i.e. the hydrogenolysis elementary step. With $82 \mathrm{~kJ} / \mathrm{mol}$ the effective barrier on $\mathrm{MgO}(100)$ was found to be similar to the barrier of $\mathrm{HRh}(\mathrm{CO})_{4}$ with $78 \mathrm{~kJ} / \mathrm{mol}$. For $\mathrm{HRh}(\mathrm{CO})_{3} \mathrm{PMe}_{3}, \quad \mathrm{Rh}_{1} / \mathrm{CeO}_{2}(111)$ and $\mathrm{Rh}_{1} / \mathrm{MgO}(301)$ the highest effective barriers were predicted for the barrier of TS2 with 72,81 and $123 \mathrm{~kJ} / \mathrm{mol}$, respectively. We note that both olefin insertion and hydrogenolysis have been proposed as ratedetermining steps, depending on substrate, catalyst and conditions. Sparta et al. have found that electron donating ligands shift the rate-determining step to olefin insertion. ${ }^{18}$ With the notable exception of $\mathrm{MgO}(301)$, the highest activation barriers do not differ significantly for the investigated catalysts.

Our computational investigation thus shows that Rh SACs can have high catalytic activities comparable to those of molecular catalysts. However, $\mathrm{Rh}_{1} / \mathrm{MgO}(301)$, the catalyst that is clearly most stable, is also by far the least active. We attribute both the increased stability and the reduced activity to the high confinement that leads to strong interaction between $\mathrm{Rh}$ and the support but limits the flexibility required for catalysis. While a systematic investigation of catalytic reactivity with scaling relations has been introduced for homogeneous catalysis and hydroformylation, ${ }^{70}$ a corresponding analysis that also accounts for the stability would be highly desirable for SACs, but needs more data than available in the present study.

Experimental investigation of $\mathrm{CeO}_{2}$ and $\mathrm{MgO}$-supported Rh SACs for styrene hydroformylation: Catalysts displaying oxide-supported isolated $\mathrm{Rh}_{1}$ centers were synthesized by oxidative re-dispersion, i.e. exploiting the high surface mobility of $\mathrm{RhO}_{\mathrm{x}}$ species at high temperatures under oxidative atmospheres. ${ }^{71}$ On the basis of the DFT results, $\mathrm{CeO}_{2}$ and $\mathrm{MgO}$ were selected as support materials. The metal content was adjusted to achieve a surface-specific Rh content of ca. 1.0 $\mathrm{Rh}_{\text {at }} \mathrm{nm}^{-2}$ on either support. X-ray diffraction showed no signs of crystalline Rh species after annealing (Figure S18) HighAngle Annular Dark-Field Scanning-Transmission Electron Microscopy (HAADF-STEM) was applied to study metal dispersion at the nanoscale (Figure $5 \mathrm{a}, \mathrm{b}$ ). On $\mathrm{CeO}_{2}$, no crystal lattices other than that of the cubic $(F m-3 m) \mathrm{CeO}_{2}$ support could be detected, suggesting the absence of Rh oxide crystallites. However, the high Z-contrast contribution from the support precluded direct discernment of $\mathrm{Rh}$ atoms. On $\mathrm{MgO}$, on the contrary, the low Z-contrast contribution from the lighter carrier enabled the direct visualization of evenly distributed and isolated $\mathrm{Rh}$ atoms. No multinuclear $\mathrm{Rh}$ species such as metal clusters or nanoparticles could be observed.
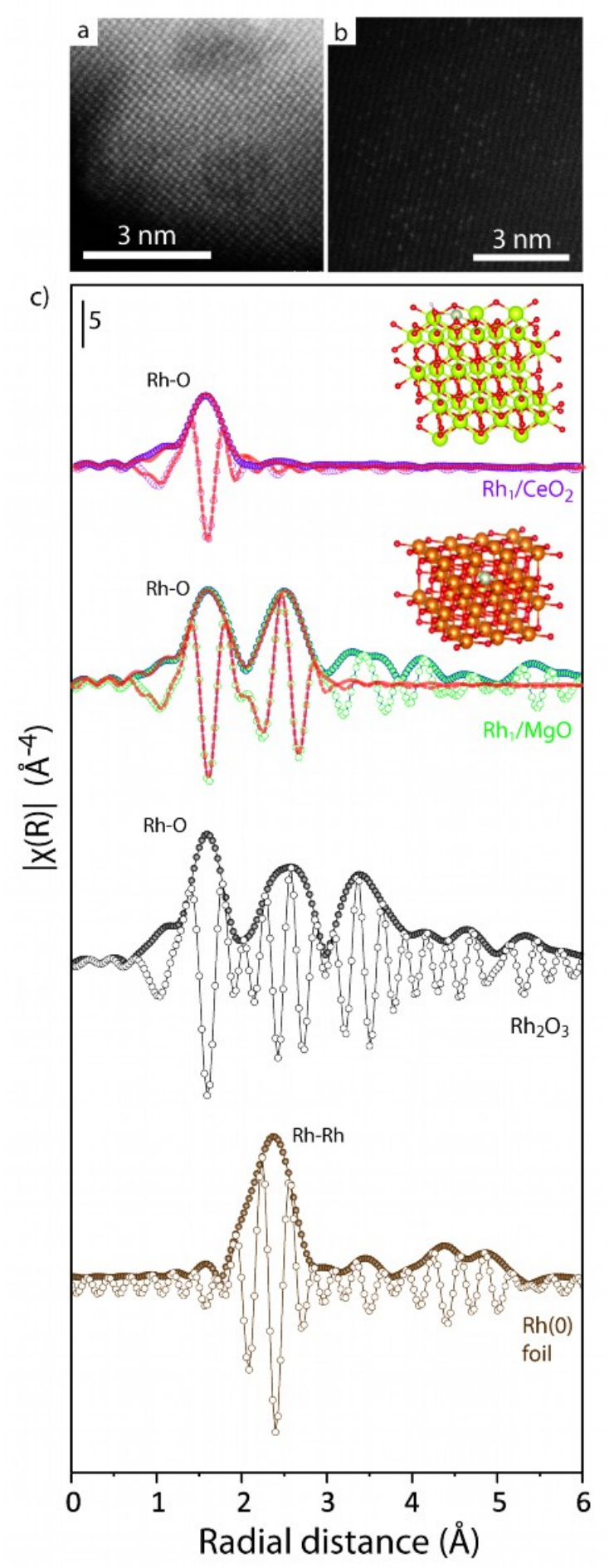

Figure 5. Representative $C_{s}-H A A D F-S T E M$ micrographs for (a) $\mathrm{Rh}_{1} / \mathrm{CeO}_{2}$, and (b) $\mathrm{Rh} / \mathrm{MgO}$ catalysts. c) FT of the $\mathbf{k}^{3}$-weighted EXAFS spectra (phase uncorrected) for $\mathrm{Rh}_{1} / \mathrm{CeO}_{2}$ and $\mathrm{Rh}_{1} / \mathrm{MgO}$ catalysts alongside the spectra for bulk oxide and metal foil references. Scatter traces correspond to experimental data (closed symbols: modulus component; open symbols: imaginary component). Full lines correspond to the fits of the experimental data to the scattering paths derived from the DFT-optimized singleatom structural models included as insets. Color code in the models: Ce (green), Mg (orange), O (red), Rh (gray). 
As a complement to the local microscopy observations, extended X-ray absorption fine structure (EXAFS) spectroscopy was applied to gain insight into the atomicity and local coordination environment of $\mathrm{Rh}$ in the catalysts. The corresponding EXAFS spectra for the oxide-supported catalysts, alongside those for reference $\mathrm{Rh}_{2} \mathrm{O}_{3}$ and $\mathrm{Rh}(0)$ reference materials also shown in Figure $5 \mathrm{c}$. One and two scattering contributions with similar amplitude were observed within radial distances in the range of 0 to $3 \AA$ for $\mathrm{Rh}_{1} / \mathrm{CeO}_{2}$ and $\mathrm{Rh}_{1} / \mathrm{MgO}$, respectively. In both cases, the $1^{\text {st }}$-shell contribution corresponds to $\mathrm{Rh}-\mathrm{O}$ scattering. Analysis of both the modulus as well as the imaginary components of the Fourier transformed experimental EXAFS spectra showed no contributions compatible with first-shell $R h-R h$ or second-shell $R h-\mathrm{O}-R h$ scattering paths in metallic or oxide clusters, indicative for the presence of mononuclear $\mathrm{Rh}$ species in the catalysts regardless of the nature of the support. The experimental spectra could be fitted to scattering paths derived from DFT-optimized structures for isolated $\mathrm{Rh}$ atoms coordinated to $\mathrm{MgO}$ and $\mathrm{CeO}_{2}$ supports, respectively (Figure $5 \mathrm{c}$ ). This analysis revealed a higher $\mathrm{Rh}-\mathrm{O}$ coordination number $(\mathrm{CN})$ in $\mathrm{Rh}_{1} / \mathrm{MgO}$ compared to the those in the $\mathrm{Rh}_{1} / \mathrm{CeO}_{2}$ counterpart. The best fit was obtained with structural models displaying $1^{\text {st }}$-shell $\mathrm{CN}_{\mathrm{Rh}-\mathrm{O}}$ of 5 and 4 for $\mathrm{Rh}_{1} / \mathrm{MgO}$ and $\mathrm{Rh}_{1} / \mathrm{CeO}_{2}$, respectively (Table S2). Altogether, these characterization results provide solid evidence for the atomic dispersion of $\mathrm{Rh}$ on both oxide supports. However, they also hint at differences in the degree of confinement experienced by the $\mathrm{Rh}_{1}$ centers as a function of the nature of the oxide carrier, with Rh atoms likely occupying positions of higher confinement (higher coordination) on $\mathrm{MgO}$ associated to surface step-edges (Figure S23).

The catalytic performance of $\mathrm{Rh}_{1} / \mathrm{CeO}_{2}$ and $\mathrm{Rh}_{1} / \mathrm{MgO} \mathrm{SACs}$ was assessed in the hydroformylation of various olefin substrates in the liquid phase. Styrene was selected as the first substrate, as the competing olefin double-bond isomerization reaction is not feasible in this case, thus simplifying the product scope. As summarized in Table $1, \mathrm{Rh}_{1} / \mathrm{CeO}_{2}$ showed to be a rather active catalyst, reaching $96 \%$ styrene conversion after $12 \mathrm{~h}$ at $363 \mathrm{~K}$. The metal-normalized TOF achieved with this $\mathrm{SAC}$ was comparable to that exhibited by a $\mathrm{HRh}\left(\mathrm{PPh}_{3}\right)_{3} \mathrm{CO}$ molecular catalyst under identical reaction settings. Moreover, $\mathrm{Rh}_{1} / \mathrm{CeO}_{2}$ showed an over fivefold higher TOF alongside a higher selectivity to aldehyde products than a reference $\mathrm{Rh} / \mathrm{C}$ solid catalyst. Undesired olefin hydrogenation was notably suppressed on the $\mathrm{CeO}_{2}$-supported monoatomic $\mathrm{Rh}_{1}$ centers. On the contrary, the selectivity to ethylbenzene side-product reached $7 \%$, even at a lower styrene conversion level of $85 \%$, on the carbon-supported $\mathrm{Rh}$ nanoparticles. In stark contrast to the $\mathrm{CeO}_{2}$-supported $\mathrm{SAC}, \mathrm{Rh}_{1} / \mathrm{MgO}$ showed essentially no catalytic activity under these reaction conditions.

Furthermore, $\mathrm{Rh}_{1} / \mathrm{CeO}_{2}$ was also effective to convert other olefins (Table 1). However, particularly in the case of aliphatic substrates, double-bond migration activity competed with hydroformylation, lowering the selectivity to aldehyde products to $<60 \%$ at olefin conversion levels $\geq 80 \%$ (Table 1 ). Experiments with $\mathrm{Rh}_{1} / \mathrm{CeO}_{2}$ at various reaction temperatures in the range of 333-363 $\mathrm{K}$ showed an apparent activation energy $\left(E_{a}\right)$ for styrene hydroformylation of $56 \mathrm{~kJ} / \mathrm{mol}$ (Figure 6 and Figure S19) and revealed that the regioselectivity of the reaction depended conspicuously on the reaction temperature (Figure S20). This is in line with previous observations with molecular catalysts in solution which showed increasing linear-tobranched ratios with increasing reaction temperature in the hydroformylation of styrene. ${ }^{72}$ With $\mathrm{Rh}_{1} / \mathrm{CeO}_{2}$ as catalyst, linear-to-branched ratios remained $<1$ in the entire temperature range screened. While the reaction regioselectivity is known to be a function of various experimental settings, this selectivity pattern is aligned with those observed for molecular $\mathrm{Rh}$ catalysts stabilized by ligands imposing comparatively lower steric effects. $^{73}$ The results thus suggest that active $\mathrm{Rh}$ monoatomic complexes on oxide surfaces are subjected to low sterical hindrance.

Table 1: Experimental conversion, TOF and selectivity for different catalytic systems. Reaction conditions: molar ratio of rhodium to substrate of $1: 500, p=10$ bar, $\mathrm{H}_{2}: \mathrm{CO}=1: 1$

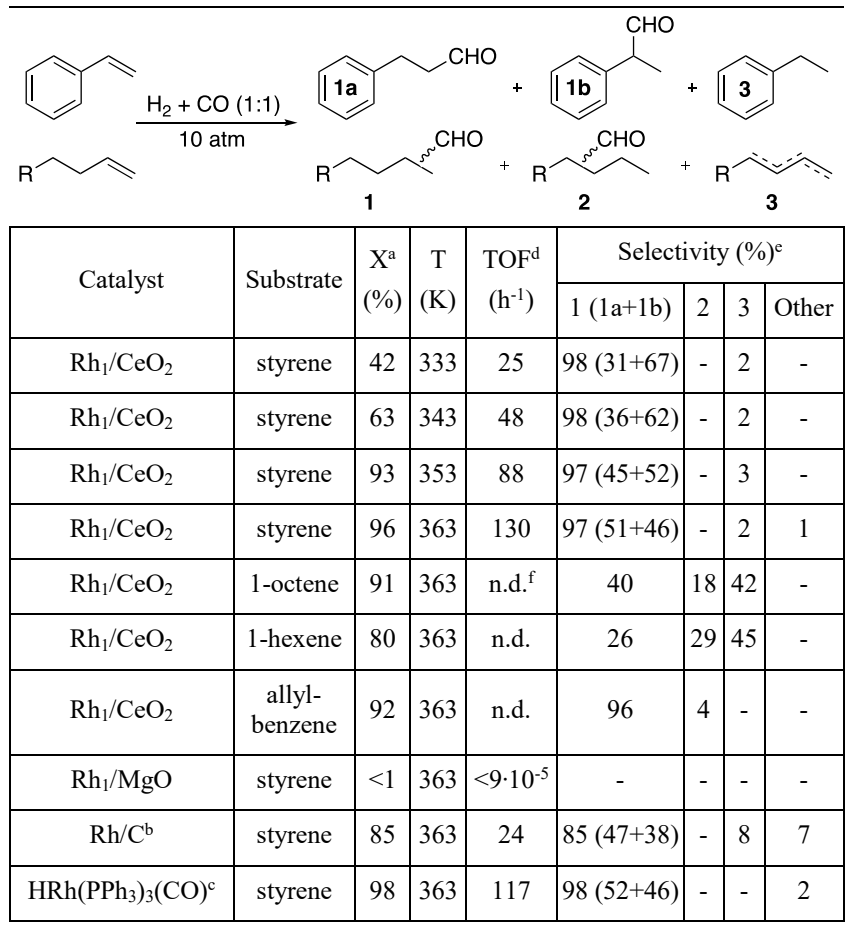

${ }^{\mathrm{a}}$ Olefin conversion after $12 \mathrm{~h} .{ }^{\mathrm{b}} 5 \mathrm{wt} \% \mathrm{Rh}$, Sigma-Aldrich. ${ }^{\mathrm{c}}$ Benzene was employed as solvent. ${ }^{\mathrm{d}}$ Turnover frequency, defined as the number of molecules of olefin substrate converted per total Rh atom and hour, as derived from initial reaction rates (see SI). ${ }^{\mathrm{e}}$ Determined after 12 h. ${ }^{\mathrm{f}}$ n.d.: not determined.

In situ XAS experiments on exposure of the $\mathrm{Rh}_{1} / \mathrm{CeO}_{2}$ catalyst to syngas up to a reaction temperature of $373 \mathrm{~K}$ showed no evidence for metal reduction and/or agglomeration. The average $R h-O$ coordination number decreased by ca. $20 \%$, suggesting a partial cleavage of $\mathrm{Rh}-\mathrm{O}$ bonds between the monoatomic $\mathrm{Rh}$ centers and the $\mathrm{CeO}_{2}$ support which is believed to create the hydroformylation active sites (Figure S19). Moreover, under the applied hydroformylation reaction conditions, hot filtration tests showed negligible further olefin conversion $(<2 \%)$ after the solid catalyst had been removed from the reaction medium by filtering the reaction liquors through a porous frit $(5 \mu \mathrm{m})$, two consecutive times, under working conditions. This result strongly indicates that the oxide supported monoatomic $\mathrm{Rh}$ species were responsible for the observed catalytic activity. Also, the marked dependence of the catalytic activity on the nature of the SAC oxide support suggests the heterogeneous nature of the catalysis. 
Figure 6. Experimental results for the hydroformylation of styrene using $\mathrm{Rh}_{1} / \mathrm{CeO}_{2} \mathrm{SAC}$. a) Styrene conversion over time at different temperatures. b) Arrhenius plot for the determination of apparent activation energy. Reaction conditions: $\quad$ Rh:olefin $=1: 500, \quad[$ lefin $]=0.33 \mathrm{mmol} / \mathrm{mL}$, $\mathrm{p}=10 \mathrm{bar}, \mathrm{H}_{2}: \mathrm{CO}=1: 1$. Time-resolved olefin conversion data for molecular $\mathrm{HRh}\left(\mathrm{PPh}_{3}\right)_{3}(\mathrm{CO})$ and solid $\mathrm{Rh} / \mathrm{C}$ benchmark catalysts is given in Figure S22 (SI).

\section{SUMMARY AND CONCLUSIONS}

Oxide-supported Rh SACs for hydroformylation catalysts were investigated using DLPNO-CCSD(T):DFT calculations. The thermodynamic stability of supported carbonyl hydride complexes $\left(\mathrm{HRh}(\mathrm{CO})_{2}\right.$, i.e. $\left.\mathrm{HRh}(\mathrm{CO})_{3}\right)$ is often limited by desorption into the gas phase or solution. The driving force for deactivation depends on temperature and $\mathrm{CO}$ pressure since the most stable complex in the gas phase, $\mathrm{HRh}(\mathrm{CO})_{4}$, contains more carbonyl ligands than the most stable adsorbed species. At operating conditions, a step edge on $\mathrm{MgO}(301)$ provides the most stable coordination site that we considered, with an adsorption free energy of $-127 \mathrm{~kJ} / \mathrm{mol}$, while most other oxide surfaces provide a stabilization of only -40 to $-80 \mathrm{~kJ} / \mathrm{mol}$. Our computational investigation of the gas-phase hydroformylation of ethene shows that some $\mathrm{SACs}, \mathrm{Rh}_{1} / \mathrm{MgO}(100)$ and $\mathrm{Rh}_{1} / \mathrm{CeO}_{2}(111)$, show a high catalytic activity that is comparable to those of molecular catalysts, with the highest activation barriers well below $100 \mathrm{~kJ} / \mathrm{mol}$ in the order of magnitude of the experimental findings. The most stable SAC, $\mathrm{Rh}_{1} / \mathrm{MgO}(301)$, however, is predicted to be significantly less active, which we attribute to the increased confinement, i.e. higher coordination with the oxide matrix, that provides stabilization but limits the reactivity. $\mathrm{CeO}_{2-}$ and $\mathrm{MgO}-$ supported $\mathrm{Rh}$ catalysts were synthesized and shown to consist of atomically dispersed Rh species. On MgO, EXAFS hints at $\mathrm{Rh}$ atoms in higher coordination environments, i.e. higher degrees of confinement, more similar to the simulations for $\mathrm{Rh}_{1} / \mathrm{MgO}(301)$ than in $\mathrm{Rh}_{1} / \mathrm{MgO}(100)$. This assignment is supported by the fact that the $\mathrm{MgO}$-supported $\mathrm{Rh} \mathrm{SAC}$ is found to be barely active for the liquid-phase hydroformylation of styrene. On the contrary, $\mathrm{Rh}_{1} / \mathrm{CeO}_{2}$ is highly active for olefin hydroformylation, showing a performance comparable to a $\mathrm{HRh}\left(\mathrm{PPh}_{3}\right)_{3} \mathrm{CO}$ molecular catalyst, while being stable towards $\mathrm{Rh}$ leaching in solution under the applied reaction conditions. Our combined experimental and theoretical study has thus shown that oxide supported single-atom rhodium catalysts can show olefin hydroformylation activities comparable to those of molecular rhodium complexes in solution. Our calculations show that desorption of the catalytic rhodium carbonyl hydride complexes must be considered as a potential deactivation pathway, since adsorption can be relatively weak. While calculations predict that higher degrees of metal oxide surface confinement can lead to higher stability, both experiment and calculations indicate that an oxide support that leads to a stable and active rhodium catalyst needs to strike a good balance between confinement for stabilization and sufficient flexibility for the catalytic reaction to proceed.

\section{ASSOCIATED CONTENT}

\section{Supporting Information}

Further details and results of the bulk and surface slab optimizations (energies and structures) and supporting experimental spectra.

The Supporting Information is available free of charge on the ACS Publications website.

Supporting Information.pdf

\section{AUTHOR INFORMATION}

\section{Corresponding Author}

*philipp.plessow@kit.edu

\section{Author Contributions}

All authors have given approval to the final version of the manuscript.

\section{ACKNOWLEDGMENT}

X-ray absorption experiments were performed at the ALBA Synchrotron Light Source (Spain), experiment 2019023278. Beamline scientists L. Simonelli and C. Marini are gratefully acknowledged for their contribution to beam setup. E. Andrés, E. Martínez-Monje, I. López and M. García-Farpón (ITQ) are acknowledged for their assistance with XAS data acquisition. J. Ternedien (MPI-KOFO) is acknowledged for the performance of XRD experiments. N. Pfänder (MPI-CEC) is acknowledged for his contribution to STEM characterization. The authors acknowledge support by the state of Baden- Württemberg through bwHPC (bwUnicluster and JUSTUS, RV bw17D01). The authors gratefully acknowledge support by the GRK 2450. Financial support from the Helmholtz Association is also gratefully acknowledged. The experimental work received funding from the Max Planck Society and the Spanish Ministry of Science, Innovation and Universities (projects SEV-2016-0683 and RTI2018-096399-A-I00). B.B. Sarma acknowledges the Alexander von Humboldt Foundation for a postdoctoral scholarship.

\section{ABBREVIATIONS}

AFM, atomic force microscopy; ALD, atomic layer deposition; ARPESS, automated relaxed potential energy surface scan; DFT, density functional theory; DLPNO-CCSD(T), domain-based localpair natural orbital coupled cluster singles doubles with perturbative triples contribution; DRIFTS, diffuse reflectance infrared Fourier transform spectroscopy; EXAFS, extended X-ray absorption fine structure spectroscopy; HAADF-STEM, high angle annular dark field scanning transition electron microscopy; PAW, projector-augmented wave; PBE, Perdew-Burke-Ernzerhof; SAC, single atom catalyst; SI, supporting information; TS, transition state; VASP, Vienna ab initio simulation package; XANES, X-ray absorption near edge spectroscopy.

\section{REFERENCES}


1. Franke, R.; Selent, D.; Borner, A., Applied hydroformylation. Chem. Rev. 2012, 112 (11), 5675-732.

2. Wiese, K.-D.; Obst, D., Hydroformylation. In Catalytic Carbonylation Reactions, Beller, M., Ed. Springer Berlin Heidelberg: Berlin, Heidelberg, 2006; pp 1-33.

3. Serna, P.; Yardimci, D.; Kistler, J. D.; Gates, B. C., Formation of supported rhodium clusters from mononuclear rhodium complexes controlled by the support and ligands on rhodium. Phys. Chem. Chem. Phys. 2014, 16 (3), 1262-1270.

4. Guan, E.; Gates, B. C., Stable Rhodium Pair Sites on MgO: Influence of Ligands and Rhodium Nuclearity on Catalysis of Ethylene Hydrogenation and $\mathrm{H}-\mathrm{D}$ Exchange in the Reaction of $\mathrm{H} 2$ with D2. ACS Catal. 2018, 8 (1), 482-487.

5. $\quad$ Dossi, C.; Fusi, A.; Garlaschelli, L.; Roberto, D.; Ugo, R.; Psaro, R., Ethylene Hydroformylation with the Silica-Supported K2[Rh12(Co)30] Cluster - Evidence for Vapor-Phase Cluster Catalysis. Catal. Lett. 1991, 11 (3-6), 335-339.

6. $\quad$ Ehresmann, J. O.; Kletnieks, P. W.; Liang, A.; Bhirud, V. A.; Bagatchenko, O. P.; Lee, E. J.; Klaric, M.; Gates, B. C.; Haw, J. F., Evidence from NMR and EXAFS Studies of a Dynamically Uniform Mononuclear Single-Site Zeolite-Supported Rhodium Catalyst. Angew. Chem. Int. Ed. Engl. 2006, 45 (4), 574-576.

7. Sun, Q.; Dai, Z. F.; Liu, X. L.; Sheng, N.; Deng, F.; Meng, X. J.; Xiao, F. S., Highly Efficient Heterogeneous Hydroformylation over RhMetalated Porous Organic Polymers: Synergistic Effect of High Ligand Concentration and Flexible Framework. J. Am. Chem. Soc. 2015, 137 (15), 5204-5209.

8. De Munck, N. A.; Verbruggen, M. W.; Scholten, J. J. F., Gas phase hydroformylation of propylene with porous resin anchored rhodium complexes part I. Methods of catalyst preparation and characterization. $J$. Mol. Catal. 1981, 10 (3), 313-330.

9. $\quad$ Lang, R.; Li, T.; Matsumura, D.; Miao, S.; Ren, Y.; Cui, Y. T.; Tan, Y.; Qiao, B.; Li, L.; Wang, A.; Wang, X.; Zhang, T., Hydroformylation of Olefins by a Rhodium Single-Atom Catalyst with Activity Comparable to RhCl(PPh3)3. Angew. Chem. Int. Ed. Engl. 2016, 55 (52), 16054-16058.

10. Yang, X. F.; Wang, A.; Qiao, B.; Li, J.; Liu, J.; Zhang, T., Singleatom catalysts: a new frontier in heterogeneous catalysis. Acc. Chem. Res. 2013, 46 (8), 1740-8.

11. Paolucci, C.; Khurana, I.; Parekh, A. A.; Li, S.; Shih, A. J.; Li, H.; Di lorio, J. R.; Albarracin-Caballero, J. D.; Yezerets, A.; Miller, J. T.; Delgass, W. N.; Ribeiro, F. H.; Schneider, W. F.; Gounder, R., Dynamic multinuclear sites formed by mobilized copper ions in NOx selective catalytic reduction. Science 2017, 357 (6354), 898.

12. Jangjou, Y.; Do, Q.; Gu, Y.; Lim, L.-G.; Sun, H.; Wang, D.; Kumar, A.; Li, J.; Grabow, L. C.; Epling, W. S., Nature of Cu Active Centers in Cu-SSZ-13 and Their Responses to SO2 Exposure. ACS Catal. 2018, 8 (2), 1325-1337.

13. Wang, L. B.; Zhang, W. B.; Wang, S. P.; Gao, Z. H.; Luo, Z. H.; Wang, X.; Zeng, R.; Li, A. W.; Li, H. L.; Wang, M. L.; Zheng, X. S.; Zhu, J. F.; Zhang, W. H.; Ma, C.; Si, R.; Zeng, J., Atomic-level insights in optimizing reaction paths for hydroformylation reaction over $\mathrm{Rh} / \mathrm{CoO}$ single-atom catalyst. Nat. Commun. 2016, 7

14. Breslow, D. S.; Heck, R. F., Mechanism of the Hydroformylation of Olefins. Chem. Ind.-London 1960, (17), 467-467.

15. Heck, R. F.; Breslow, D. S., The Reaction of Cobalt Hydrotetracarbonyl with Olefins. J. Am. Chem. Soc. 1961, 83 (19), 40234027.

16. Leeuwen, P. W. N. M.; Claver, C., Rhodium Catalyzed Hydroformylation. Springer Netherlands: Dordrecht, 2002.

17. Van Rooy, A., Rhodium-catalysed hydroformylation of branched 1-alkenes; bulky phosphite vs. triphenylphosphine as modifying ligand. J. Organomet. Chem. 1996, 507 (1-2), 69-73.

18. Sparta, M.; Borve, K. J.; Jensen, V. R., Activity of rhodiumcatalyzed hydroformylation: Added insight and predictions from theory. J. Am. Chem. Soc. 2007, 129 (27), 8487-8499.

19. Gellrich, U.; Himmel, D.; Meuwly, M.; Breit, B., Realistic energy surfaces for real-world systems: an IMOMO CCSD(T):DFT scheme for rhodium-catalyzed hydroformylation with the 6-DPPon ligand. Chem. Eur. J. 2013, 19 (48), 16272-81.

20. Kumar, M.; Chaudhari, R. V.; Subramaniam, B.; Jackson, T. A., Ligand Effects on the Regioselectivity of Rhodium-Catalyzed
Hydroformylation: Density Functional Calculations Illuminate the Role of Long-Range Noncovalent Interactions. Organometallics 2014, 33 (16), 4183-4191.

21. Jiao, Y. Z.; Torne, M. S.; Gracia, J.; Niemantsverdriet, J. W.; van Leeuwen, P. W. N. M., Ligand effects in rhodium-catalyzed hydroformylation with bisphosphines: steric or electronic? Catal. Sci. Technol. 2017, 7 (6), 1404-1414.

22. Schmidt, S.; DegImann, P.; Hofmann, P., Density Functional Investigations of the Rh-Catalyzed Hydroformylation of 1,3-Butadiene with Bisphosphite Ligands. ACS Catal. 2014, 4 (10), 3593-3604.

23. Jacobs, I.; de Bruin, B.; Reek, J. N. H., Comparison of the Full Catalytic Cycle of Hydroformylation Mediated by Mono- and Bis-Ligated Triphenylphosphine-Rhodium Complexes by Using DFT Calculations. Chemcatchem 2015, 7 (11), 1708-1718.

24. Kegl, T., Computational aspects of hydroformylation. RSC Adv. 2015, 5 (6), 4304-4327.

25. Wodrich, M. D.; Busch, M.; Corminboeuf, C., Accessing and predicting the kinetic profiles of homogeneous catalysts from volcano plots. Chem. Sci. 2016, 7 (9), 5723-5735.

26. Liu, J.; Bunes, B. R.; Zang, L.; Wang, C. Y., Supported singleatom catalysts: synthesis, characterization, properties, and applications. Environ. Chem. Lett. 2018, 16 (2), 477-505.

27. Kwon, Y.; Kim, T. Y.; Kwon, G.; Yi, J.; Lee, H., Selective Activation of Methane on Single-Atom Catalyst of Rhodium Dispersed on Zirconia for Direct Conversion. J. Am. Chem. Soc. 2017, 139 (48), 1769417699.

28. Qiao, B.; Wang, A.; Yang, X.; Allard, L. F.; Jiang, Z.; Cui, Y.; Liu J.; Li, J.; Zhang, T., Single-atom catalysis of $\mathrm{CO}$ oxidation using Pt1/FeOx. Nat. Chem. 2011, 3 (8), 634-41.

29. Sun, S. H.; Zhang, G. X.; Gauquelin, N.; Chen, N.; Zhou, J. G.; Yang, S. L.; Chen, W. F.; Meng, X. B.; Geng, D. S.; Banis, M. N.; Li, R. Y.; Ye, S. Y.; Knights, S.; Botton, G. A.; Sham, T. K.; Sun, X. L., Single-atom Catalysis Using Pt/Graphene Achieved through Atomic Layer Deposition. Sci. Rep.-UK 2013, 3 (1).

30. Abbet, S.; Sanchez, A.; Heiz, U.; Schneider, W. D.; Ferrari, A. M.; Pacchioni, G.; Rösch, N., Acetylene Cyclotrimerization on Supported Size-Selected PdnClusters $(1 \leq n \leq 30)$ : One Atom Is Enough! J. Am. Chem. Soc. 2000, 122 (14), 3453-3457.

31. Lin, J.; Wang, A.; Qiao, B.; Liu, X.; Yang, X.; Wang, X.; Liang, J.; Li, J.; Liu, J.; Zhang, T., Remarkable performance of $\mathrm{Ir} 1 / \mathrm{FeO}(\mathrm{x})$ singleatom catalyst in water gas shift reaction. J. Am. Chem. Soc. 2013, 135 (41), 15314-7.

32. Gu, X.-K.; Qiao, B.; Huang, C.-Q.; Ding, W.-C.; Sun, K.; Zhan, E.; Zhang, T.; Liu, J.; Li, W.-X., Supported Single Pt1/Au1 Atoms for Methanol Steam Reforming. ACS Catal. 2014, 4 (11), 3886-3890.

33. Jones, J.; Xiong, H. F.; Delariva, A. T.; Peterson, E. J.; Pham, H.; Challa, S. R.; Qi, G. S.; Oh, S.; Wiebenga, M. H.; Hernandez, X. I. P.; Wang, Y.; Datye, A. K., Thermally stable single-atom platinum-on-ceria catalysts via atom trapping. Science 2016, 353 (6295), 150-154.

34. Fei, H.; Dong, J.; Arellano-Jimenez, M. J.; Ye, G.; Dong Kim, N.; Samuel, E. L.; Peng, Z.; Zhu, Z.; Qin, F.; Bao, J.; Yacaman, M. J.; Ajayan, P. M.; Chen, D.; Tour, J. M., Atomic cobalt on nitrogen-doped graphene for hydrogen generation. Nat. Commun. 2015, 6 (1), 8668.

35. Kwon, Y.; Kim, T. Y.; Kwon, G.; Yi, J.; Lee, H., Selective Activation of Methane on Single-Atom Catalyst of Rhodium Dispersed on Zirconia for Direct Conversion. J Am Chem Soc 2017, 139 (48), 1769417699.

36. Wei, H.; Liu, X.; Wang, A.; Zhang, L.; Qiao, B.; Yang, X.; Huang, Y.; Miao, S.; Liu, J.; Zhang, T., FeOx-supported platinum single-atom and pseudo-single-atom catalysts for chemoselective hydrogenation of functionalized nitroarenes. Nat. Commun. 2014, 5 (1), 5634.

37. Wang, X.; van Bokhoven, J. A.; Palagin, D., Atomically dispersed platinum on low index and stepped ceria surfaces: phase diagrams and stability analysis. Phys. Chem. Chem. Phys. 2020, 22 (1), 28-38.

38. Neitzel, A.; Figueroba, A.; Lykhach, Y.; Skala, T.; Vorokhta, M.; Tsud, N.; Mehl, S.; Sevcikova, K.; Prince, K. C.; Neyman, K. M.; Matolin, V.; Libuda, J., Atomically Dispersed Pd, Ni, and Pt Species in Ceria-Based Catalysts: Principal Differences in Stability and Reactivity. J. Phys. Chem. C 2016, 120 (18), 9852-9862.

39. Tang, Y.; Asokan, C.; Xu, M.; Graham, G. W.; Pan, X.; Christopher, P.; Li, J.; Sautet, P., Rh single atoms on TiO2 dynamically 
respond to reaction conditions by adapting their site. Nat. Commun. 2019, $10(1), 4488$.

40. DeRita, L.; Resasco, J.; Dai, S.; Boubnov, A.; Thang, H. V.; Hoffman, A. S.; Ro, I.; Graham, G. W.; Bare, S. R.; Pacchioni, G.; Pan, X.; Christopher, P., Structural evolution of atomically dispersed Pt catalysts dictates reactivity. Nat. Mater. 2019, 18 (7), 746-751.

41. Su, Y. Q.; Wang, Y. F.; Liu, J. X.; Filot, I. A. W.; Alexopoulos, K.; Zhang, L.; Muravev, V.; Zijlstra, B.; Vlachos, D. G.; Hensen, E. J. M., Theoretical Approach To Predict the Stability of Supported Single-Atom Catalysts. ACS Catal. 2019, 9 (4), 3289-3297.

42. O’Connor, N. J.; Jonayat, A. S. M.; Janik, M. J.; Senftle, T. P., Interaction trends between single metal atoms and oxide supports identified with density functional theory and statistical learning. Nat. Catal. 2018, 1 (7), 531-539.

43. Perdew, J. P.; Burke, K.; Ernzerhof, M., Generalized Gradient Approximation Made Simple. Phys. Rev. Lett. 1996, 77 (18), 3865-3868.

44. Grimme, S.; Antony, J.; Ehrlich, S.; Krieg, H., A consistent and accurate $a b$ initio parametrization of density functional dispersion correction (DFT-D) for the 94 elements H-Pu. J. Chem. Phys. 2010, 132 (15), 154104.

45. Kresse, G.; Joubert, D., From ultrasoft pseudopotentials to the projector augmented-wave method. Phys. Rev. B 1999, 59 (3), 1758-1775.

46. Kresse, G.; Furthmuller, J., Efficient iterative schemes for $a b$ initio total-energy calculations using a plane-wave basis set. Phys. Rev. $B$ 1996, 54 (16), 11169-11186.

47. Blochl, P. E., Projector augmented-wave method. Phys. Rev. $B$ 1994, 50 (24), 17953-17979.

48. Song, Y. L.; Yin, L. L.; Zhang, J.; Hu, P.; Gong, X. Q.; Lu, G. Z., A DFT plus $U$ study of $\mathrm{CO}$ oxidation at $\mathrm{CeO} 2(110)$ and (111) surfaces with oxygen vacancies. Surf. Sci. 2013, 618, 140-147.

49. Nolan, M.; Grigoleit, S.; Sayle, D. C.; Parker, S. C.; Watson, G. W., Density functional theory studies of the structure and electronic structure of pure and defective low index surfaces of ceria. Surf. Sci. 2005, 576 (1-3), 217-229.

50. Huang, M.; Fabris, S., CO adsorption and oxidation on ceria surfaces from DFT+U calculations. J. Phys. Chem. C 2008, 112 (23), 86438648.

51. Monkhorst, H. J.; Pack, J. D., Special Points for Brillouin-Zone Integrations. Phys. Rev. B 1976, 13 (12), 5188-5192.

52. Plessow, P. N., Efficient Transition State Optimization of Periodic Structures through Automated Relaxed Potential Energy Surface Scans. J. Chem. Theory Comput. 2018, 14 (2), 981-990.

53. Zhao, Y.; Truhlar, D. G., The M06 suite of density functionals for main group thermochemistry, thermochemical kinetics, noncovalent interactions, excited states, and transition elements: two new functionals and systematic testing of four M06-class functionals and 12 other functionals. Theor. Chem. Acc. 2008, 120 (1), 215-241.

54. Stephens, P. J.; Devlin, F. J.; Chabalowski, C. F.; Frisch, M. J., Ab-Initio Calculation of Vibrational Absorption and Circular-Dichroism Spectra Using Density-Functional Force-Fields. J. Phys. Chem. 1994, 98 (45), 11623-11627.

55. TURBOMOLE V.7.1 2016, a development of Karlsruhe Institute of Technology, Karlsruhe, 1989-2019, TURBOMOLE GmbH, since 2007; available from http://www.turbomole.com. Turbomole GmbH: 2016.

56. Weigend, F., Accurate Coulomb-fitting basis sets for $\mathrm{H}$ to $\mathrm{Rn}$. Phys. Chem. Chem. Phys. 2006, 8 (9), 1057-65.

57. Weigend, F.; Ahlrichs, R., Balanced basis sets of split valence, triple zeta valence and quadruple zeta valence quality for $\mathrm{H}$ to $\mathrm{Rn}$ : Design and assessment of accuracy. Phys. Chem. Chem. Phys. 2005, 7 (18), $3297-$ 305 .

58. Neese, F., The ORCA program system. Wiley Interdiscip. Rev. Comput. Mol. Sci. 2012, 2 (1), 73-78.

59. Neese, F., Software update: the ORCA program system, version 4.0. Wiley Interdiscip. Rev. Comput. Mol. Sci. 2018, 8 (1), e1327.

60. Ekström, U.; Visscher, L.; Bast, R.; Thorvaldsen, A. J.; Ruud, K., Arbitrary-Order Density Functional Response Theory from Automatic Differentiation. J. Chem. Theory Comput. 2010, 6 (7), 1971-1980.

61. Andrae, D.; Haeussermann, U.; Dolg, M.; Stoll, H.; Preuss, H., Energy-adjustedab initio pseudopotentials for the second and third row transition elements. Theor. Chim. Acta 1990, 77 (2), 123-141.

62. Marenich, A. V.; Cramer, C. J.; Truhlar, D. G., Universal Solvation Model Based on Solute Electron Density and on a Continuum Model of the Solvent Defined by the Bulk Dielectric Constant and Atomic Surface Tensions. J. Phys. Chem. B 2009, 113 (18), 6378-6396.

63. Riplinger, C.; Pinski, P.; Becker, U.; Valeev, E. F.; Neese, F., Sparse maps--A systematic infrastructure for reduced-scaling electronic structure methods. II. Linear scaling domain based pair natural orbital coupled cluster theory. J. Chem. Phys. 2016, 144 (2), 024109.

64. Ugliengo, P.; Damin, A., Are dispersive forces relevant for CO adsorption on the $\mathrm{MgO}(001)$ surface? Chem. Phys. Lett. 2002, 366 (5-6), 683-690.

65. Alessio, M.; Usvyat, D.; Sauer, J., Chemically Accurate Adsorption Energies: $\mathrm{CO}$ and $\mathrm{H} 2 \mathrm{O}$ on the $\mathrm{MgO}(001)$ Surface. J. Chem. Theory Comput. 2019, 15 (2), 1329-1344.

66. Utamapanya, S.; Klabunde, K. J.; Schlup, J. R., Nanoscale MetalOxide Particles Clusters as Chemical Reagents - Synthesis and Properties of Ultrahigh Surface-Area Magnesium-Hydroxide and Magnesium-Oxide. Chem. Mater. 1991, 3 (1), 175-181.

67. Ravel, B.; Newville, M., ATHENA, ARTEMIS, HEPHAESTUS: data analysis for X-ray absorption spectroscopy using IFEFFIT. J. Synchrotron Radiat. 2005, 12 (4), 537-541.

68. CRC handbook of chemistry and physics: a ready-reference book of chemical and physical data. 87. ed., 2006-2007 ed.; CRC, Taylor \& Francis: Boca Raton, Fla., 2006.

69. Connett, J. E., Chemical equilibria 5. Measurement of equilibrium constants for the dehydrogenation of propanol by a vapour flow technique. J. Chem. Thermodyn. 1972, 4 (2), 233-237.

70. Wodrich, M. D.; Busch, M.; Corminboeuf, C., Expedited Screening of Active and Regioselective Catalysts for the Hydroformylation Reaction. Helv. Chim. Acta 2018, 101 (9), e1800107.

71. Goula, G.; Botzolaki, G.; Osatiashtiani, A.; Parlett, C.; Kyriakou, G.; Lambert, R. M.; Yentekakis, I. V., Oxidative Thermal Sintering and Redispersion of Rh Nanoparticles on Supports with High Oxygen Ion Lability. Catalysts 2019, 9 (6).

72. Lazzaroni, R.; Raffaelli, A.; Settambolo, R.; Bertozzi, S.; Vitulli, G., Regioselectivity in the rhodium-catalyzed hydroformylation of styrene as a function of reaction temperature and gas pressure. J. Mol. Catal. 1989, 50 (1), 1-9.

73. Yu, S.; Chie, Y.-m.; Guan, Z.-h.; Zou, Y.; Li, W.; Zhang, X., Highly Regioselective Hydroformylation of Styrene and Its Derivatives Catalyzed by Rh Complex with Tetraphosphorus Ligands. Org. Lett. 2009, 11 (1), 241244. 


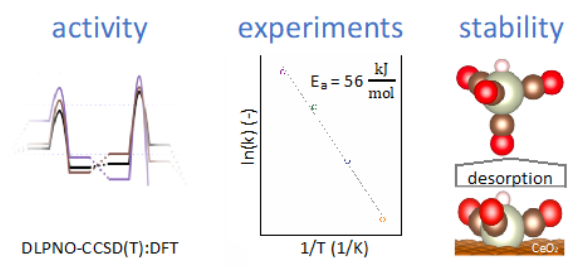

